\title{
Effects of 12-month home-based physiotherapy on duration of living at home and functional capacity among older persons with signs of frailty or with a recent hip fracture - protocol of a randomized controlled trial (HIPFRA study)
}

\author{
Paula Soukkio ${ }^{{ }^{* \dagger}} \mathbb{B}$, Sara Suikkanen ${ }^{1 \dagger}$, Sanna Kääriä ${ }^{4}$, Hannu Kautiainen ${ }^{3}$, Sarianna Sipilä²,
} Katriina Kukkonen-Harjula ${ }^{1}$ and Markku Hupli ${ }^{1}$

\begin{abstract}
Background: Health concerns, such as frailty and osteoporotic fractures decrease functional capacity and increase use of health and social care services in the aging population. The ability to continue living at home is dependent on functional capacity, which can be enhanced by rehabilitation.

We study the effects of a 12-month home-based physiotherapy program with 12-month follow-up on duration of living at home, functional capacity, and the use of social and health care services among older persons with signs of frailty, or with a recently operated hip fracture.

Methods: This is a non-blinded, parallel group, randomized controlled trial performed in South Karelia Social and Health Care District, Finland (population 131,000). Three hundred community-dwelling older persons with signs of frailty (age $\geq 65$ ) and 300 persons with a recent hip fracture (age $\geq 60$ ) will be recruited. Frailty is screened by FRAIL questionnaire and verified by modified Fried's frailty criteria. Both patient groups will be randomized separately to a physiotherapy and a usual care arm. Individualized, structured and progressive physiotherapy will be carried out for 60 min, twice a week for 12 months at the participant's home. The primary outcome at 24 months is duration of living at home. Our hypothesis is that persons assigned to the physiotherapy arm will live at home for six months longer than those in the usual care arm. Secondary outcomes are functional capacity, frailty status, health-related quality-of-life, falls, use and costs of social and health care services, and mortality. Assessments, among others Short Physical Performance Battery, Functional Independence Measure, Mini Nutritional Assessment, and Mini-Mental State Examination will be performed at the participant's home at baseline, 3, 6, and 12 months. Register data on the use and costs of social and health care services, and mortality will be monitored for 24 months.

Discussion: Our trial will provide new knowledge on the potential of intensive, long-term home-based physiotherapy among older persons at risk for disabilities, to enhance functional capacity and thereby to postpone the need for institutional care, and diminish the use of social and health care services.

(Continued on next page)
\end{abstract}

\footnotetext{
* Correspondence: paula.soukkio@eksote.fi

†Paula Soukkio and Sara Suikkanen contributed equally to this work.

${ }^{1}$ Rehabilitation, South Karelia Social and Health Care District, Valto Käkelän

katu 3, Fl-53130 Lappeenranta, Finland

Full list of author information is available at the end of the article
}

(c) The Author(s). 2018 Open Access This article is distributed under the terms of the Creative Commons Attribution 4.0 International License (http://creativecommons.org/licenses/by/4.0/), which permits unrestricted use, distribution, and reproduction in any medium, provided you give appropriate credit to the original author(s) and the source, provide a link to the Creative Commons license, and indicate if changes were made. The Creative Commons Public Domain Dedication waiver (http://creativecommons.org/publicdomain/zero/1.0/) applies to the data made available in this article, unless otherwise stated. 
(Continued from previous page)

Trial registration: ClinicalTrials.gov Identifier: NCT02305433, Registered Nov 28, 2014.

Keywords: Frail elderly, Hip fractures, Community-dwelling, Home-based physiotherapy, Duration of living at home, Functional capacity, Social and health care services

\section{Background}

In the aging population, one of the major burdens in social and health care is frailty. Frailty is a multidimensional condition, related to poor resolution of homeostasis after stressor events [1-3]. It can lead to increased vulnerability, disability, risk of falling, need for long-term care, mortality [1-3], and is associated with increased health care costs [4]. Hip fractures are another major burden causing morbidity, impairments, increased need for care, and mortality [5-7]. The yearly economic burden of hip fractures in Europe alone is estimated to be over 16 billion euros [7].

In persons over 65 years the prevalence of frailty varies depending on the criteria used, being from 4 to $59 \%[8,9]$. The most common definition is based on the frailty phenotype [1], which includes five criteria: unintentional weight loss, exhaustion, physical inactivity, slow walking speed, and weak grip strength. The prevalence of frailty increases with age and is higher among women than among men [10]. Both frailty and pre-frailty states are significant predictors of nursing home placement [11].

Worldwide the incidence of hip fractures varies widely and is highest in North Western Europe [12]. In western countries $10-20 \%$ of the persons are institutionalized when evaluated 6-12 months after the hip fracture [13], and $11 \%$ change their dwelling (from home to institution or vice versa) during 4-12 months after the fracture [14]. At one year since the fracture $42 \%$ of the patients have not recovered to their pre-fracture mobility level, and $29 \%$ do not achieve the same level of activities of daily living that they had before the fracture [15]. Excess mortality during the first post-fracture year of hip fracture patients is $8-36 \%$ [16]. Frailty is common among hip fracture patients [17], and the frailty status influences the recovery [18].

Physical activity has beneficial effects on muscle strength and endurance in older adults [19]. Frailty is an indication to start physical exercise [19] to improve functional capacity [20]. Multicomponent exercise interventions (including aerobic, strength, balance and flexibility exercises) reduce the incidence, prevalence and severity of frailty [21, 22], and enhance functional capacity [18, 23] and overall mobility [24] of hip fracture patients.

To our knowledge, long-term home-based physiotherapy and whether it can prolong duration of living at home have not been studied extensively in community-dwelling older persons with signs of frailty or with a recently operated hip fracture. Our objective is to study the effects of a structured 12-month home-based physiotherapy program with 12-month follow-up on duration of living at home, functional capacity, and the use of social and health care services. The main hypothesis is that home-based physiotherapy lengthens the duration of living at home by six months as compared to usual care in both patient groups. We also hypothesize that physiotherapy improves functional capacity, and decreases the use and costs of social and health care services.

\section{Methods \\ Design}

HIPFRA study is a parallel group, non-blinded, randomized controlled trial carried out in Finland, in South Karelia Social and Health Care District (Eksote), population 131,000, of whom 25\% were 65 years or older in 2015 . The study lasts for 24 months and has two phases; 1 ) home-based physiotherapy intervention for the first 12 months, and 2) registry follow-up for the second 12 months. The study has started in December 2014 and the final follow-up period ends in December 2019. For a more detailed timetable, see Fig. 1.

\section{Outcomes of the study}

The primary outcome is duration of living at home. The secondary outcomes are functional capacity, frailty status, health-related quality-of-life, and number of falls, use and costs of social and health care services, and mortality.

\section{Participants and eligibility criteria}

The target population is older adults with signs of frailty or with a recently operated hip fracture, who live at home, are able to walk indoors without or with mobility aids, and are able to communicate in Finnish.

For persons with signs of frailty the inclusion criteria are: 1) one or more points from FRAIL questionnaire [25] (screening), 2) one or more points from modified Fried et al.'s frailty criteria [1] (verification), 3) age 65 or older, and 4) Mini-Mental State Examination (MMSE) [26] score $\geq 17$. For hip fracture patients the inclusion criteria are 1) ICD-10 diagnosis codes S72.0, S72.1, $S 72.2,2)$ the index fracture is the first operated one in the present hip, 3) age 60 or older, and 4) Mini-Mental State Examination (MMSE) [26] score $\geq 12$.

Exclusion criteria for both patient groups are: 1) resident in institutional care, 2) advanced diseases which prevent from participating in long-term physiotherapy, 


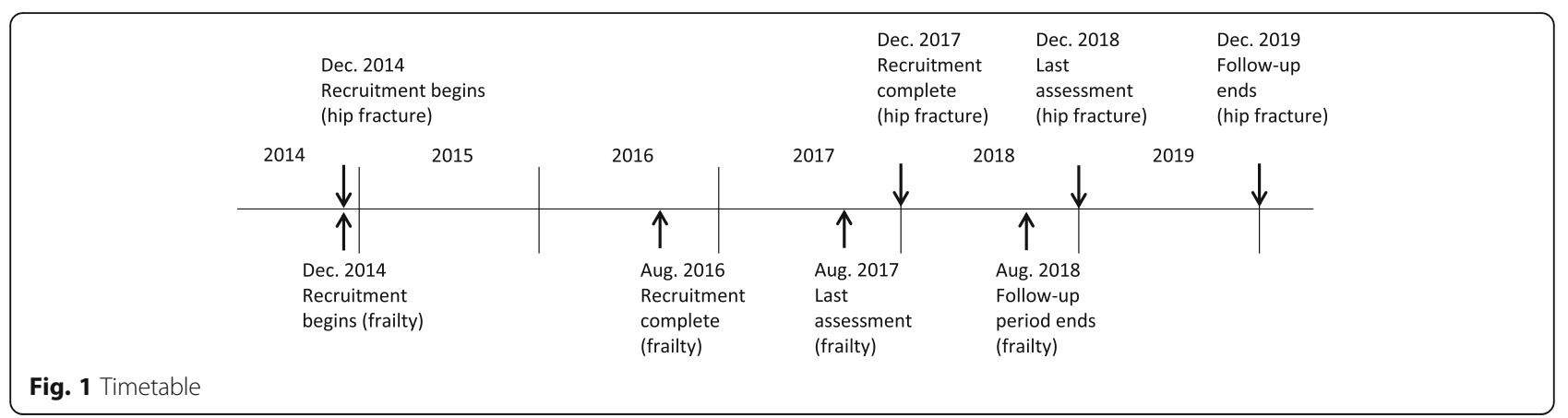

such as severe neurological diseases (e.g. multiple sclerosis, cerebrovascular disorders), cardiovascular diseases with severely impaired physical capacity (NYHA class III or IV), severe musculoskeletal diseases (e.g. severe rheumatoid arthritis), or severe or acute mental problems (major depression, psychosis or schizophrenia), 3) alcohol or drug abuse, 4) severe problems with hearing or eyesight, or 5) terminal illnesses.

\section{Randomization}

A computer-generated random allocation sequence was prepared by a statistician at University of Helsinki. The statistician is not involved in the management of patients. The two patient groups are randomized separately to a home-based physiotherapy and a usual care arm. Random allocation is performed by the project manager using the computer program, in consecutive order after baseline assessments. The randomization block size varies from 2 to 10 and the sequence is concealed. The project manager informs the participant by telephone about the allocation result. If the participant is allocated to the physiotherapy arm, the manager also informs the physiotherapist by telephone about the new rehabilitee, and physiotherapy starts within a week.

\section{Recruitment \\ Recruitment of persons with signs of frailty}

Potential participants are informed about the study by advertisements in local newspapers or by Eksote personnel. The recruitment process has two phases (Fig. 2). First, frailty screening is carried out using FRAIL questionnaire [25] either in face-to-face contacts or over the phone by Eksote personnel. In the second phase, the study nurse visits the person's home, gives oral and written information about the study, checks that all the inclusion criteria and none of the exclusion criteria are fulfilled, and verifies the frailty status using modified Fried's criteria [1]. The criteria were modified by assessing physical activity using the question on frequency of physical activity according to Health Behaviour and Health of the Finnish Elderly survey [27], and by using a cut-off value of $8.7 \mathrm{~s}$ for the 4-m walking time, which is based on the lowest quarter for persons aged 71 and older in Short Physical Performance Battery [28].

\section{Recruitment of persons with a recent hip fracture}

Recruitment begins at Eksote Rehabilitation Inpatient Center, to which the majority of the hip fracture patients are transferred from Eksote orthopedic wards in less than a week after surgery. The study nurse meets possibly eligible patients in the rehabilitation inpatient center and gives them oral and written information about the study. For those who are interested in participating, a home visit is performed by the nurse within a week after discharge. The content of the home visit is the same as for the persons with signs of frailty.

\section{Assessments}

Previously validated methods for data collection are used in HIPFRA study. Information about the main outcome, duration of living at home, is retrieved from the electronic health records (EHR) of Eksote. The duration of living at home is defined as number of days lived at home during 24 months. Days spent in hospital or in institutional care reduces the number of days lived at home. Change to reside permanently in institutional care or death (within 24 months) are defined as end points.

Interviews, questionnaires, measurements and register information are used to collect data for secondary outcomes. Measurements and interviews based on structured questionnaires are performed at baseline, and after 3,6 , and 12 months at the participant's home by the study physiotherapist or the study nurse, who are not blinded to randomization. The visit lasts approximately for one and half hours. Before the baseline assessment the participant signs a written informed consent. Before visits the participants are mailed self-reported questionnaires. Register information (for $0-24$ months) on the use and costs of social and health care services, medication and mortality will be retrieved from Eksote EHR, the Population Register Centre, and the registers of the Social Insurance Institution (for 0-24 months). Assessment methods of outcomes and other parameters, and 


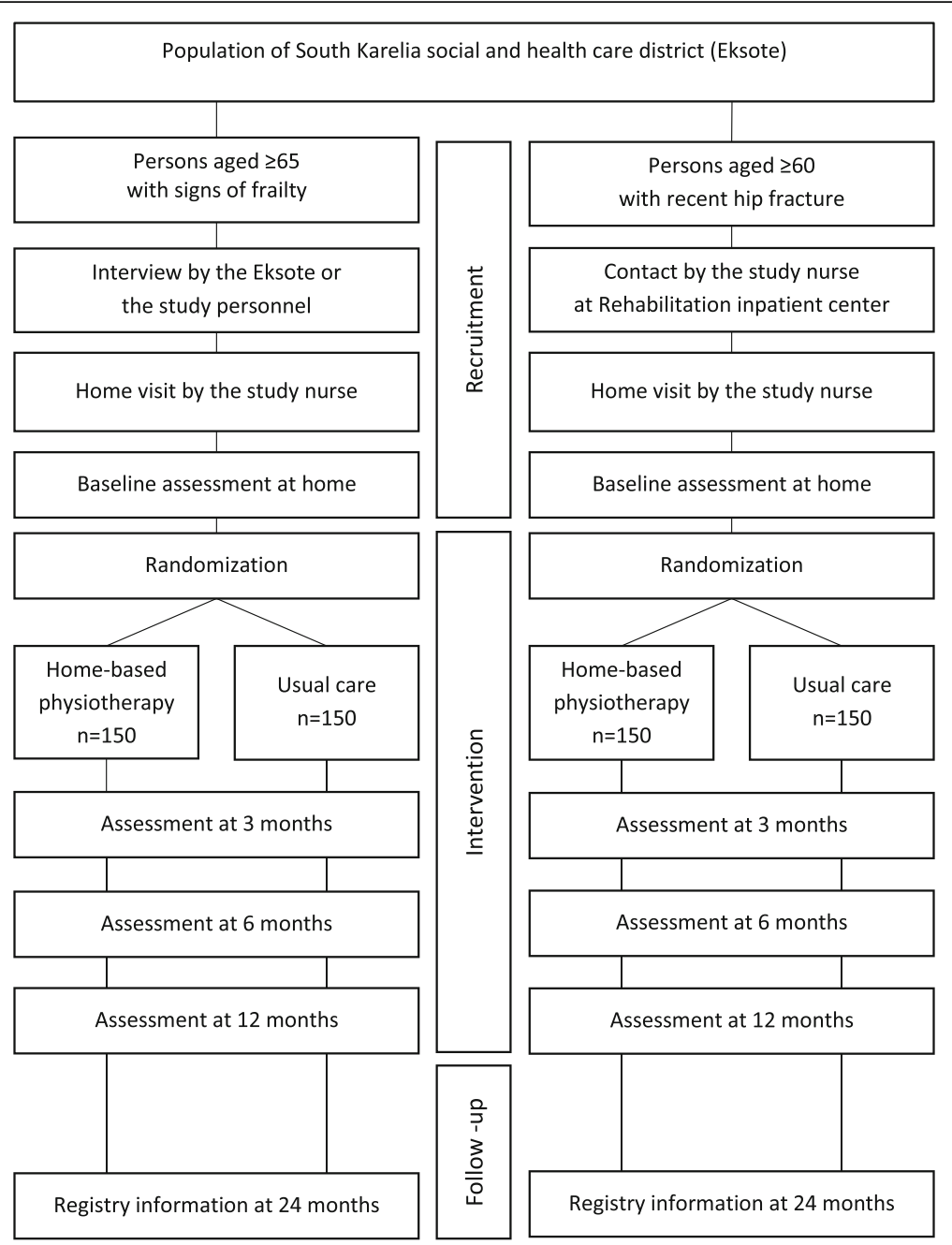

Fig. 2 Flow chart

the assessment schedule during 24 months are presented in Table 1.

\section{Home-based physiotherapy intervention}

The goal is to restore and increase the participant's functional capacity, especially in activities of daily living, to prolong duration of living at home. One supervised physiotherapy session at the participant's home lasts for $60 \mathrm{~min}$, and takes place twice a week for 12 months. The participant has the same physiotherapist throughout the year. Physiotherapy is structured and progressive and consists of multicomponent exercises (Table 2). An individual physiotherapy plan is prepared by the physiotherapist in cooperation with the participant. The goal setting is done by using the Goal Attainment Scaling (GAS) method [29, 30]. Goals are evaluated and reported after 3, 6 and 12 months of therapy by the physiotherapist and the participant. The dates, duration, content (type, intensity, perceived exertion, and the number of sets and repetitions), and any adverse effects of each physiotherapy session are reported monthly by the physiotherapist.

\section{Exercises for muscle strength, power and endurance}

The goal is to enhance the participant's muscle strength, power and endurance, especially in lower limbs, in order to improve postural balance, ability to walk, and functional capacity. Physiotherapy starts with a 2-3-week orientation period based on the Otago exercise program [31]. Strength training is progressive, and follows a cycle where 8-week periods of strength, power and endurance exercises alternate during the intervention year. The intensity goal of strength exercises is $60-80 \%$ from the person's maximal strength of the trained muscle [32-34]. Sets per muscle vary from 2 to 5 , and repetitions per set vary from 3 to 12. Muscle power exercises are performed with low to moderate intensity (20-60\%) [32], and with high velocity of movement. In power exercises approximately 3 
Table 1 Outcomes, assessment methods and schedule

\begin{tabular}{|c|c|c|c|c|c|c|c|c|}
\hline \multirow[t]{2}{*}{ Outcomes } & \multirow[t]{2}{*}{$\begin{array}{l}\text { Parameters and measures } \\
\text { [reference] }\end{array}$} & \multirow[t]{2}{*}{ Scale } & \multirow[t]{2}{*}{ Assessment method } & \multicolumn{5}{|c|}{$\begin{array}{l}\text { Assessment time points } \\
\text { (months from the beginning) }\end{array}$} \\
\hline & & & & 0 & 3 & 6 & 12 & 24 \\
\hline Primary outcome & $\begin{array}{l}\text { Duration of living at home } \\
\text { (days) during } 24 \text { months }\end{array}$ & $1-730$ & Register information & & & & & $x$ \\
\hline \multicolumn{9}{|l|}{ Secondary outcomes } \\
\hline \multirow[t]{4}{*}{ Functional capacity } & $\begin{array}{l}\text { Instrumental Activities of } \\
\text { Daily Living (IADL) [54] }\end{array}$ & $8-31$ & $\begin{array}{l}\text { Interview based on a } \\
\text { structured questionnaire }\end{array}$ & $x$ & $x$ & $x$ & $x$ & \\
\hline & $\begin{array}{l}\text { Functional Independence } \\
\text { Measure (FIM) [55] }\end{array}$ & $18-126$ & $\begin{array}{l}\text { Interview based on a } \\
\text { structured questionnaire }\end{array}$ & $x$ & $x$ & $x$ & $x$ & \\
\hline & $\begin{array}{l}\text { Short Physical Performance } \\
\text { Battery (SPPB) }[28,56]\end{array}$ & $0-12$ & Measurement & $x$ & $x$ & $x$ & $x$ & \\
\hline & $\begin{array}{l}\text { Grip strength (Saehan } \\
\text { dynamometer, model } \\
\text { Sh5001, South Korea) [57] }\end{array}$ & & Measurement & $x$ & $x$ & $x$ & $x$ & \\
\hline Frailty status & $\begin{array}{l}\text { Fried et al.'s frailty criteria } \\
\text { (modified) [1] }\end{array}$ & $0-5$ & $\begin{array}{l}\text { Interview based on a } \\
\text { structured questionnaire } \\
\text { and measurement }\end{array}$ & $x$ & & & $x$ & \\
\hline Quality-of-life & $\begin{array}{l}\text { Health-related quality-of-life } \\
\text { (HRQoL) (15D@) }[58,59]\end{array}$ & $15-75$ & Self-reported questionnaire & $x$ & $x$ & $x$ & $x$ & \\
\hline Falls & Number of falls & & $\begin{array}{l}\text { Interview based on a } \\
\text { structured questionnaire }\end{array}$ & $x$ & $x$ & $x$ & $x$ & \\
\hline Service use and costs & $\begin{array}{l}\text { Use and costs of social and } \\
\text { health care services, and } \\
\text { medication }\end{array}$ & & $\begin{array}{l}\text { Register data (0-12 months } \\
\text { and 13-24 months) from EHR } \\
\text { and Social Insurance Institution }\end{array}$ & & & & $x$ & $x$ \\
\hline Mortality & Mortality & & Register data from EHR & & & & & $x$ \\
\hline \multicolumn{9}{|l|}{ Other outcomes } \\
\hline Cognition & $\begin{array}{l}\text { Mini-Mental State Examination } \\
\text { (MMSE) [26] }\end{array}$ & $0-30$ & $\begin{array}{l}\text { Interview based on a structured } \\
\text { questionnaire }\end{array}$ & $x$ & & $x$ & $x$ & \\
\hline Depressive symptoms & $\begin{array}{l}\text { Geriatric Depression Scale } \\
\text { (GDS-15) [60] }\end{array}$ & $0-15$ & $\begin{array}{l}\text { Interview based on a structured } \\
\text { questionnaire }\end{array}$ & $x$ & $x$ & $x$ & $x$ & \\
\hline Nutritional status & $\begin{array}{l}\text { Mini Nutritional Assessment } \\
\text { (MNA) [38] }\end{array}$ & $0-30$ & $\begin{array}{l}\text { Interview based on a structured } \\
\text { questionnaire }\end{array}$ & $x$ & $x$ & $x$ & $x$ & \\
\hline Fear of falling & $\begin{array}{l}\text { Falls Efficacy Scale International } \\
(\text { FES-I) }[61,62]\end{array}$ & $16-64$ & $\begin{array}{l}\text { Interview based on a structured } \\
\text { questionnaire }\end{array}$ & $x$ & $x$ & $x$ & $x$ & \\
\hline Social support & Social Provision Scale (SPS) [63] & $24-96$ & Self-reported questionnaire & $x$ & & $x$ & $x$ & \\
\hline \multirow[t]{10}{*}{ Health status } & Weight (Omron HN289, Japan) & & Measurement & $x$ & $x$ & $x$ & $x$ & \\
\hline & $\begin{array}{l}\text { Height (KaWe PERSON-CHECK, } \\
\text { Germany) }\end{array}$ & & Measurement & $x$ & $x$ & $x$ & $x$ & \\
\hline & BMI & & Calculated from weight and height & $x$ & $x$ & $x$ & $x$ & \\
\hline & $\begin{array}{l}\text { Diseases diagnosed by a } \\
\text { physician }\end{array}$ & & $\begin{array}{l}\text { Interview based on a structured } \\
\text { questionnaire and EHR }\end{array}$ & $x$ & & & $x$ & \\
\hline & Medication & & $\begin{array}{l}\text { Interview based on a structured } \\
\text { questionnaire and EHR }\end{array}$ & $x$ & $x$ & $x$ & $x$ & \\
\hline & $\begin{array}{l}\text { Pain (Visual Analogue } \\
\text { Scale, VAS) [64] }\end{array}$ & $0-100$ & $\begin{array}{l}\text { Interview based on a structured } \\
\text { questionnaire }\end{array}$ & $x$ & $x$ & $x$ & $x$ & \\
\hline & Medical and mobility aids & & $\begin{array}{l}\text { Interview based on a structured } \\
\text { questionnaire and EHR }\end{array}$ & $x$ & $x$ & $x$ & $x$ & \\
\hline & Perceived health [27] & & $\begin{array}{l}\text { Interview based on a structured } \\
\text { questionnaire }\end{array}$ & $x$ & $x$ & $x$ & $x$ & \\
\hline & $\begin{array}{l}\text { Perceived mobility and } \\
\text { physical fitness [27] }\end{array}$ & & $\begin{array}{l}\text { Interview based on a structured } \\
\text { questionnaire }\end{array}$ & $x$ & $x$ & $x$ & $x$ & \\
\hline & $\begin{array}{l}\text { Hip fracture surgery (details } \\
\text { of operation, inpatient rehabilitation) }\end{array}$ & & EHR & $x$ & & & & \\
\hline
\end{tabular}


Table 1 Outcomes, assessment methods and schedule (Continued)

\begin{tabular}{|c|c|c|c|c|c|c|c|c|}
\hline \multirow[t]{2}{*}{ Outcomes } & \multirow[t]{2}{*}{$\begin{array}{l}\text { Parameters and measures } \\
\text { [reference] }\end{array}$} & \multirow[t]{2}{*}{ Scale } & \multirow[t]{2}{*}{ Assessment method } & \multicolumn{5}{|c|}{$\begin{array}{l}\text { Assessment time points } \\
\text { (months from the beginning) }\end{array}$} \\
\hline & & & & 0 & 3 & 6 & 12 & 24 \\
\hline \multirow[t]{2}{*}{ Home services } & Home care and home health care & & $\begin{array}{l}\text { Interview based on a structured } \\
\text { questionnaire and EHR }\end{array}$ & $x$ & $x$ & $x$ & $x$ & \\
\hline & Home renovations & & $\begin{array}{l}\text { Interview based on a structured } \\
\text { questionnaire and EHR }\end{array}$ & $x$ & $x$ & $x$ & $x$ & \\
\hline \multirow[t]{3}{*}{ Lifestyle } & Physical activity [27] & & $\begin{array}{l}\text { Interview based on a structured } \\
\text { questionnaire }\end{array}$ & $x$ & $x$ & $x$ & $x$ & \\
\hline & $\begin{array}{l}\text { Alcohol consumption } \\
\text { (AUDIT-C) [65] }\end{array}$ & $0-12$ & $\begin{array}{l}\text { Interview based on a structured } \\
\text { questionnaire }\end{array}$ & $x$ & $x$ & $x$ & $x$ & \\
\hline & Smoking [27] & & $\begin{array}{l}\text { Interview based on a structured } \\
\text { questionnaire }\end{array}$ & $x$ & $x$ & $x$ & $x$ & \\
\hline \multirow[t]{2}{*}{ Background information } & $\begin{array}{l}\text { Demographic factors (age, } \\
\text { marital, status, education, } \\
\text { previous occupation) }\end{array}$ & & $\begin{array}{l}\text { Interview based on a structured } \\
\text { questionnaire }\end{array}$ & $x$ & & & & \\
\hline & Type of dwelling and household & & $\begin{array}{l}\text { Interview based on a structured } \\
\text { questionnaire }\end{array}$ & $x$ & $x$ & $x$ & $x$ & \\
\hline
\end{tabular}

sets and repetitions from 4 to 10 are used [35]. Endurance exercises consist of at least 12 and up to $15-30$ repetitions per set, and 2-3 sets per muscle, and the intensity is 20 $60 \%$ from the person's maximal strength of the trained muscle [34].

Strength training is individually tailored, and training sets and repetitions are modified according to the participant's performance [32], health status, and perceived exertion rated by the Borg Rating of Perceived Exertion Scale (RPE, scale 6 to 20) [36] during every session. Progression is achieved by adding resistance with extra weights, such as ankle weights, weight vests, kettlebells and dumbbells, and modifying the sets and repetitions during 12 months.

\section{Balance and flexibility exercises}

The goal for balance exercises is to enhance the participant's functional capacity and ability to walk in order to prevent falls. Balance training begins with the Otago exercise program [31], and later on functional exercises are used. The goal for flexibility exercises is to enhance the participant's range of motion especially in ankle joints and in large joints to maintain activities of daily living. Dynamic flexibility exercises are performed in every

Table 2 Contents of home-based physiotherapy

\begin{tabular}{|c|c|c|c|c|c|}
\hline & Warm-up & Strength exercises & Flexibility exercises & Balance exercises & Functional exercises \\
\hline $\begin{array}{l}\text { Modes of } \\
\text { activities }\end{array}$ & Various activities & $\begin{array}{l}\text { Orientation } 2-3 \text { weeks: based } \\
\text { on the Otago exercise program [31] } \\
\text { ( } 5 \text { leg muscle strengthening } \\
\text { exercises with up to } 4 \text { levels } \\
\text { of difficulty). } \\
\text { Muscle strength, power and } \\
\text { endurance periods, each } \\
8 \text { weeks, repeated twice } \\
\text { during } 12 \text { months }\end{array}$ & $\begin{array}{l}\text { Various flexibility } \\
\text { exercises for large } \\
\text { joints and the spine } \\
\text { to enlarge the ROM }\end{array}$ & $\begin{array}{l}\text { Otago [31] exercises } \\
\text { (12 balance exercises } \\
\text { with up to } 4 \text { levels of } \\
\text { difficulty) }\end{array}$ & $\begin{array}{l}\text { Flexibility, strength and } \\
\text { balance exercises combined } \\
\text { with IADL activities and } \\
\text { walking outside }\end{array}$ \\
\hline Intensity & Low to moderate & $\begin{array}{l}\text { Moderate to vigorous } \\
\text { (12-17 of RPE) [36] }\end{array}$ & Moderate & $\begin{array}{l}\text { Challenges to the } \\
\text { individual's balance } \\
\text { abilities }\end{array}$ & $\begin{array}{l}\text { Challenges to the individual's } \\
\text { functional abilities }\end{array}$ \\
\hline Progression & $\begin{array}{l}\text { Changing intensity } \\
\text { and activities according } \\
\text { to physical condition }\end{array}$ & $\begin{array}{l}\text { Using extra weights, } \\
\text { increasing the level } \\
\text { of difficulty }\end{array}$ & Changing activities & $\begin{array}{l}\text { Selecting more } \\
\text { advanced balance } \\
\text { exercises (e.g. static, } \\
\text { dynamic, dual task) }\end{array}$ & $\begin{array}{l}\text { Selecting more advanced } \\
\text { functional exercises }\end{array}$ \\
\hline Frequency & 2 times / week & 2 times / week & 2 times / week & 2 times / week & One time / week \\
\hline Duration & Approx. 5-10 min & Approx. 30 min & Approx. 10 min & Approx. 20 min & $\begin{array}{l}\text { Integrated to other } \\
\text { exercises }\end{array}$ \\
\hline Assessment & Shortness of breath & SPPB $[28,56], \operatorname{RPE}[36]$ & $\mathrm{ROM}$ & Time (s), observation & Task accomplishment \\
\hline
\end{tabular}

IADL Instrumental Activities of Daily Living, ROM Range of motion, RPE Rating of Perceived Exertion (scale 6 to 20), $s$ second(s), SPPB Short Physical Performance Battery 
physiotherapy session as warm-up exercises or combined with functional exercises.

\section{Functional exercises}

Functional exercises, such as climbing stairs, chair rise, and walking outside are used to train muscle strength and endurance. Activities of daily living, such as washing dishes, preparing meals, doing laundry or cleaning up are used to train flexibility and balance abilities. Functional exercises are more effective than resistance exercises to improve functional task performance [37].

\section{Counselling on physical activity and nutrition}

The physiotherapist encourages the participant to exercise on their own, and if possible to take part in the exercise groups organized by municipalities or by third sector organizations. Brief nutritional counselling by the physiotherapist is based on the MNA test [38] and national nutritional guidelines. The main goal of guidance is to reverse possible malnutrition, and ensure sufficient protein intake to prevent weight loss and sarcopenia. Oral nutritional supplements are recommended if necessary.

\section{Usual care}

The participants in the usual care arm continue to live their life "as usual". They can get any social or health care services that they may need during the 24 months they participate in the study.

\section{Statistical analyses}

The statistical power calculations are based on the hypothesis that the persons with hip fracture assigned to the physiotherapy arm will live at home for six months (180 days) longer than those in the control arm when assessed at 24 months. Our calculations are based on the Finnish PERFECT (PERFormance, Effectiveness and Cost of Treatment episodes) data on hip fractures [39], in which data are available on the proportion of patients living at home 1 year after the fracture (in 2005). To detect a difference of 180 days between the arms, when the type I error is set at 0.05 and the statistical power at 0.8 , a sample size of 91 persons in each arm is needed. To allow for discontinuation (estimated as 15\% of the participants) and death of patients (20\%) during our study period of 2 years, our targeted sample is 300 patients. As to the power calculations of patients with signs of frailty, there are no previous data on the duration of living at home. Therefore we use the same power calculations as for patients with hip fracture. However, the mortality of frail patients is assumed to be lower than that of hip fracture patients.

Frequencies, means and standard deviations will be used to describe background variables of the participants. Differences between the physiotherapy and usual care arm at baseline will be tested by chi-squared test or Fisher exact test for categorical variables, and by t-test or bootstrap type test for continuous variables as appropriate. Analyses will be carried out according to intention to treat. Repeated data will be analyzed using generalized estimating equations (GEE) models with appropriate distribution and link function. In the case of violation of the assumptions (e.g. non-normality), a bootstrap-type test will be used. The normality of the variables will be tested by using the Shapiro-Wilk W test. Incidence rates with $95 \%$ confidence intervals $(\mathrm{CI})$ will be calculated assuming a Poisson distribution. Crude and standard estimates of incidence rate ratios (IRR) will be calculated using Poisson regression models, or negative binomial regression models when appropriate. Generalized linear regression model with log link and gamma variance functions will be estimated for social and health service use and costs. Variance function will be selected based on Park test and Akaike's information criterion. Mortality and its risk factors will be assessed with Cox proportional hazard regression models. Analyses will be performed using IBM SPSS statistics 24 software.

\section{Ethical issues}

During recruitment, comprehensive oral and written information of the study is given to persons interested in participating in the study. Participation is voluntary. If they are eligible and willing, they sign an informed consent before the baseline assessment. All data collected will be recorded, stored and reported anonymously. This study was approved by an independent coordinating ethics committee in Helsinki University Hospital (HUS). The study was prospectively registered in ClinicalTrials.gov (NCT02305433) on November 28, 2014.

\section{Discussion}

We study the effects of long-term home-based physiotherapy in community-dwelling older persons with signs of frailty and recently operated hip fracture in randomized settings to postpone institutionalization. Our main interests are on the duration of living at home, functional capacity, and the use and costs of social and health care services.

In older persons with signs of frailty, interventions using physical exercises have improved functional outcomes such as gait speed and SPPB score [40]. However, the results on quality-of-life [41] or on balance and ADL functions [40] are not consistent. In community-dwelling older adults, exercise interventions have been effective in reducing or preventing frailty [42]. Persons with signs of frailty seem to benefit from multicomponent exercise programs, but the optimal program content still remains unclear [43, 44]. In persons with signs of frailty, individually instructed and supervised exercise has been more effective on physical functioning than group exercises [41]. The duration of therapy has most often lasted for three months (from 1 to 
18 months), and interventions for at least 5 months had better outcomes than shorter ones [45].

After hip fracture, ordinary postoperative care is not usually sufficient to maximize performance recovery [18], as recuperation time for balance and gait can be up to 9 months and for walking speed up to 11 months [46]. Extended exercise programs have had positive impact on functional capacity [47], and reducing or reversing disability of hip fracture patients $[18,23]$. Specifically, extended exercise programs outside the hospital (e.g. at home) improve physical functioning [24, 47]. Similarity to persons with signs of frailty, there is also evidence for hip fracture patients that individualized, multicomponent and progressive rehabilitation enhance functional capacity $[18,23]$.

The physiotherapy intervention in our randomized study lasts for 12 months with maximally 104 physiotherapy sessions. Participation for 12 months in physiotherapy requires strong commitment, motivation and resiliency from the patients. In Baltimore hip fracture studies [48, 49] on average 44 of 56 home exercise sessions were completed during 12 months. This implies that it is possible to engage frail older persons with hip fracture to a year-long home-based exercise intervention [49]. Physiotherapy performed at home can enhance training adherence for older persons with lower functional capacity [48], because no travelling is required. Interventions with longer durations have usually more dropouts than shorter ones [45]. On the other hand, supervised training and long-term physiotherapy relationship between the physiotherapist and the participant may improve the participant's motivation and attitude towards training, which enables progression and increased training intensity [50].

Cognitively impaired patients are often excluded from rehabilitation studies [51] even if there is evidence that for example, hip fracture patients with mild or moderate dementia [52] or community-dwelling persons with Alzheimer's disease [53] clearly benefit from intensive geriatric rehabilitation. This is why we accept mildly cognitively impaired persons (MMSE $\geq 17$ points) in our frailty group, and moderately cognitively impaired persons (MMSE 212 ) in our hip fracture group.

During the last decade, the focus in social and health care services for older persons in Eksote and generally in Finland has changed from facility-based services to services at home to enhance longer community-dwelling. Thus there is a need to study the effects and cost-effectiveness of home-based services, e.g. physiotherapy. In this pragmatic trial we implement long-term home-based physiotherapy intervention and evaluate it with repeated comprehensive assessments at home. We apply screening tools to identify community-dwelling persons with signs of frailty, who might benefit from long-term physiotherapy. Later on, frailty screening could be used in primary health care to identify community-dwelling persons in need for more intense services in order to prevent deterioration, loss of functional capacity and institutionalization.

HIPFRA study will provide new knowledge on whether an individualized, multicomponent, long-term and supervised home-based physiotherapy can improve functional capacity, diminish the degree of frailty, prolong living at home by postponing institutional care, and diminish the use of social and health care services and decrease their costs in persons with signs of frailty and in persons with recently operated hip fracture.

\section{Abbreviations \\ 15DO: 15-dimensional health-related quality-of-life instrument; AUDIT- C: Alcohol Use Disorders Identification Test; EHR: Electronic health records; Eksote: South Karelia Social and Health Care District; FES-I: Falls Efficacy Scale International; FIM: Functional Independence Measure; FRAIL: Fatigue, Resistance, Ambulation, Illnesses, \& Loss of Weight; GDS-15: Geriatric Depression Scale; HIPFRA: Home physiotherapy for HIP fracture and FRAilty; HRQOL: Health-related quality-of-life; IADL: Instrumental Activities of Daily living; MMSE: Mini-Mental State Examination; MNA: Mini Nutritional Assessment; NYHA: New York Heart Association; SPPB: Short Physical Performance Battery; SPS: Social Provision Scale; VAS: Visual Analogue Scale \\ Funding \\ HIPFRA study has two external funding bodies, The Social Insurance Institution of Finland (SII, register number 94/331/2013) and the State Research Funding for Academic Health Research (Ministry of Social Affairs and Health). Both of these are governmental funding sources. The third funding body is South Karelia Social and Health Care District (Eksote, register number 1236/00.01.05.01/2013). The funding bodies had no role in the design of the study, in collection, analysis and interpretation of data, and in writing the manuscript.}

\section{Availability of data and materials}

Data sharing is not applicable to this study protocol article as no datasets were analyzed during the current article.

\section{Authors' contributions}

$\mathrm{MH}$ and SK conceived the research idea, drew the study design and applied and received study funding from the Social Insurance Institution of Finland and Eksote. MH, SK, KKH, PS, and SSu initiated the planning of study protocol. MH, SK, KKH, PS, SSu and SSi finalized the plan. PS, SSu and KKH wrote the initial draft of the manuscript. PS, SSu, MH, SK, KKH, SSi and HK participated in writing of the manuscript, and revised it critically. All authors have given the final approval of the version to be published and have access to the final trial dataset. PS and SSu have equal contribution to the manuscript.

\section{Ethics approval and consent to participate}

The HIPFRA study has been evaluated in the Helsinki University Hospital's (HUS) Coordinating Ethics Committee. The study protocol was approved by the coordinating ethics committee on Nov 14, 2014 (document identification number 253/13/03/00/14). Some minor amendment to the research protocol of HIPFRA study documents was made in spring 2017, and approved by the HUS Coordinating Ethics Committee on March 21, 2017 (HUS/891/2017). This study will comply with the Declaration of Helsinki and the Finnish legislation on Medical research act (488/1999, changed 295/2004, 794/2010, 143/2015). All participants are given both oral and written information about the study and they sign an informed consent before randomization.

\section{Consent for publication}

Not applicable.

\section{Competing interests}

The authors declare that they have no competing interests.

\section{Publisher's Note}

Springer Nature remains neutral with regard to jurisdictional claims in published maps and institutional affiliations. 


\section{Author details}

'Rehabilitation, South Karelia Social and Health Care District, Valto Käkelän katu 3, Fl-53130 Lappeenranta, Finland. ${ }^{2}$ Gerontology Research Center, Unit of Health Sciences, University of Jyväskylä, Rautpohjankatu 8, FI-40700 Jyväskylä, Finland. ${ }^{3}$ Department of General Practice and Helsinki University Hospital, University of Helsinki, Unit of Primary Health Care, Tukholmankatu 8 B, Fl-00290 Helsinki, Finland. ${ }^{4}$ Aureolis Oy, Hevosenkenkä 3, Fl-02600 Espoo, Finland.

\section{Received: 10 July 2017 Accepted: 12 September 2018}

Published online: 01 October 2018

\section{References}

1. Fried LP, Tangen CM, Walston J, Newman AB, Hirsch C, Gottdiener J, et al. Cardiovascular health study collaborative research group. Frailty in older adults: evidence for a phenotype. J Gerontol A Biol Sci Med Sci. 2001;56: 146-56.

2. Morley JE, Vellas B, Abellan van Kan G, Anker SD, Bauer JM, Bernabei R, et al. Frailty concensus: a call to action. J Am Med Dir Assoc. 2013;14:392-7.

3. Clegg A, Young J, Illiffe S, Rikkert MO, Rockwood K. Frailty in elderly people. Lancet. 2013;381:752-62.

4. Bock JO, Köning HH, Brenner H, Haefeli WE, Quinzler R, Matschinger $H$, et al. Associations of frailty with health care costs - results of the ESTHER cohort study. BMC Health Serv Res. 2016;16:128.

5. Braithwaite RS, Col NF, Wong JB. Estimating hip fracture morbidity, mortality and costs. J Am Geriatr Soc. 2003:51:364-70.

6. Marks R. Hip fracture epidemiological trends, outcomes, and risk factors, 1970-2009. Int J Gen Med. 2010;3:1-17.

7. Pisani P, Renna MD, Conversano F, Casciaro E, Di Paola M, Quarta E, et al Major osteoporotic fragility fractures: risk factor updates and societal impact. World J Orthop. 2016:7:171-81.

8. Collard RM, Boter H, Schoevers RA, Oude Voshaar RC. Prevalence of frailty in community-dwelling older persons: a systematic review. J Am Geriatr Soc. 2012;60:1487-92

9. Theou O, Cann L, Blodgett J, Wallace LMK, Brothers TD, Rockwood K. Modification to the frailty phenotype criteria: systematic review of the current literature and investigation of 262 frailty phenotypes in the survey of health, ageing and retirement in Europe. Ageing Res Rev. 2015;21:78-94.

10. Cesari M, Prince M, Thiygarajan JA, Araujo De Carvalho I, Bernabei R, Chan P, et al. Frailty: An emerging public health priority. J Am Med Dir Assoc. 2016; 17:188-92

11. Kojima G. Frailty as predictor of nursing home placement among community-dwelling older adults: a systematic review and meta-analysis. J Geriatr Phys Ther. 2016;00:1-7.

12. Kanis JA, Odén A, McCloskey EV, Johansson H, Wahl DA, Cooper C. A systematic review of hip fracture incidence and probability of fracture worldwide. Osteoporosis Int. 2012;23:2239-56.

13. Dyer SM, Crotty M, Fairhall N, Magaziner J, Beaupre LA, Cameron ID, et al. A critical review of the long-term disability outcomes following hip fracture. BMC Geriatr. 2016:16:158.

14. Hongisto MT, Nuotio M, Luukkaala T, Väistö O, Pihlajamäki HK. Does cognitive/physical screening in an outpatient setting predict institutionalization after hip fracture? BMC Musculoskelet Disord. 2016;17: 444.

15. Bertram M, Norman R, Kemp L, Vos T. Review of long-term disability associated with hip fractures. Injury Prevention. 2011;17:365-70.

16. Abrahamsen $B$, van Staa $T$, Olson M, Cooper C. Excess mortality following hip fracture: a systematic epidemiological review. Osteoporosis Int. 2009;20: 1633-50.

17. Kistler EA, Nicholas JA, Kates SL, Friedman SM. Frailty and short term outcomes in patients with hip fracture. Geriatr Orthoped Surg Rehabil. 2015; 6:2019-214.

18. Beaupre LA, Binder EF, Cameron ID, Jones CA, Orwig D, Sherrington C, Magaziner J. Maximising functional recovery following hip fracture in frail seniors. Best Pract Res Clin Rheumatol. 2013;27:771-88.

19. Landi F, Marzetti E, Martone AM, Bernabei R, Onder G. Exercise as a remedy for sarcopenia. Curr Opin Clin Nutr Metab Care. 2014;17:25-31.

20. Cadore EL, Rodríguez-Mañas L, Sinclair A, Izquierdo M. Effects of different exercise interventions on risk of falls, gait ability, and balance in physically frail older adults: a systematic review. Rejuvenation Res. 2013;16:105-4.
21. Cameron ID, Fairhall N, Langron C, Lockwood K, Monaghan N, Aggar C, et al. A multifactorial interdisciplinary intervention reduces frailty in older people: randomized trial. BMC Med. 2013. https://doi.org/10.1186/17417015-11-65.

22. Cesari M, Vellas B, Hsu F-C, Newman AB, Doss H, King AC, et al. A physical activity intervention to treat the frailty syndrome in older persons - results from the LIFE-P study. J Gerontol A Biol Sci Med Sci. 2015;70:216-2.

23. Salpakoski A, Törmäkangas T, Edgren J, Kallinen M, Sihvonen SE, Arkela M, et al. Effects of multicomponent home-based physical rehabilitation program on mobility recovery after hip fracture: a randomized controlled trial. J Am Med Dir Assoc. 2014;15:361-8.

24. Diong J, Allen N, Sherrington C. Structured exercise improves mobility after hip fracture: a meta-analysis with meta-regression. Br J Sports Med. 2016:50: 346-55

25. Morley JE, Malmstrom TK, Miller DK. A simple frailty questionnaire (FRAIL) predicts outcomes in middle aged African Americans. J Nutr Health Aging. 2012;16:601-8.

26. Folstein MF, Folstein SE, McHug PR. "Mini mental state". A practical method for grading the cognitive state of patients for the clinician. J Psychiatr Res. 1975;12:189-98.

27. Helldán A, Helakorpi S. Health Behaviour and Health among the Finnish elderly, Spring 2013, with trends 1993-2013. National Institute for Health and Welfare (THL), Report 15/2014. http://urn.fi/URN:ISBN:978-952-302-188-4. Accessed 3 July 2017

28. Guralnik JM, Ferrucci L, Pieper CF, Leveille SG, Markides KS, Ostir GV, et al. Lower extremity function and subsequent disability: consistency across studies, predictive models, and value of gait speed alone compared with the short physical performance battery. J Gerontol Med Sci. 2000;55A:221-31.

29. Kiresuk TJ, Sherman RE. Goal attainment scaling: a general method for evaluating comprehensive community mental health programs. Community Ment Health J. 1968:4:443-53.

30. Turner-Stokes L. Goal attainment scaling (GAS) in rehabilitation: a practical guide. Clin Rehabil. 2009;23:362-70.

31. Thomas S, Mackintosh S, Halbert J. Does the 'Otago exercise programme' reduce mortality and falls in older adults? : A systematic review and metaanalysis. Age Ageing. 2010:39:681-7.

32. Avers $D$, Brown M. White paper: strength training for the older adult. J Geriatr Phys Ther. 2009:32:148-52 158.

33. Chodzko-Zajko W, Proctor DN, Fiatarone Singh MA, Minson CT, Nigg CR, Saslem GJ, et al. Exercise and physical activity for older adults. Med Sci Sports Exerc. 2009;7:1510-30

34. Cadore EL, Pinto RS, Bottaro M, Izquierdo M. Strength and endurance training prescription in healthy and frail elderly. Aging Dis. 2014;5:183-95.

35. Hazell T, Kenno K, Jakobi J. Functional benefit of power training for older adults. J Aging Phys Act. 2007;15:349-59.

36. Borg GA. Psychophysical bases of perceived exertion. Med Sci Sports Exerc. 1982:14:377-1.

37. de Vreede PL, Samson MM, van Meeteren NL, Duursma SA, Verhaar HJ. Functional-tasks exercise versus resistance strength exercise to improve daily function in older women: a randomized, controlled trial. J Am Geriatr Soc. 2005:53:2-10.

38. Vellas B, Villars H, Abellan G, Soto ME, Rolland Y, Guigoz Y, et al. Overview of the $M N A^{\oplus}$ - its history and challenges. J Nutr Health Aging. 2006;10:456-65.

39. Sund $R$, Juntunen M, Lüthje P, Huusko T, Häkkinen U. Monitoring the performance of hip fracture treatment in Finland. Ann Med. 2011;43(Supp 1):39-46.

40. Giné-Garriga M, Roqué-Fíguls M, Coll-Plana L, Sitjà-Rabert M, Salvà A Physical exercise interventions for improving performance-based measures of physical function in community-dwelling, frail older adults: a systematic review and meta-analysis. Arc Phys Med Rehab. 2014;95:753-69.

41. de Vries NM, van Ravensberg CD, Hobbelen JSM, Olde Rikkert MGM, Staal JB. Nijhuis-van der Sanden MWG. Effects of physical exercise therapy on mobility, physical functioning, physical activity, physical disability and/or multi-morbidity: a meta-analysis. Ageing Res Rev. 2012;11:136-49.

42. Puts MTE, Toubasi S, Andrew MK, Ashe MC, Ploeg J, Atkinson E, et al. Interventions to prevent or reduce the level of frailty in communitydwelling older adults: a scoping review of the literature and international policies. Age Ageing. 2017:46:383-92.

43. De Labra C, Guimares-Pinheiro C, Maseda A, Lorendo T, Millán-Calenti JC. Effects of physical exercise interventions in frail older adults: a systematic review of randomized controlled trials. BMC Geriatr. 2015;15:154. 
44. Bauman A, Merom D, Bull FC, Buchner DM, Fiatarone Singh MA. Updating the evidence for physical activity: summative reviews of the epidemiological evidence, prevalence, and interventions to promote "active aging". Gerontologist. 2016;56:268-80.

45. Theou O, Stathokostas L, Roland KP, Jakobi JM, Patterson C, Vandervoort AA, et al.. The effectiveness of exercise interventions for the management of frailty: a systematic review. J Aging Res. 2011. https://doi.org/10.4061/2011/569194.

46. Magaziner J, Hawkes W, Hebel JR, Zimmerman SI, Fox KM, Dolan M, et al. Recovery from hip fracture. J Gerontol. 2000;55A:498-507.

47. Auais MA, Eilayyan O, Mayo NE. Extended exercise rehabilitation after hip fracture improves patient's physical function: a systematic review and metaanalysis. Phys Ther. 2012;92:1437-51.

48. Orwig DL, Hochberg M, Yu-Yahiro J, Resnick B, Hawkes WG, Shardell M, et al. Delivery and outcomes of a yearlong home exercise program after hip fracture. A randomized controlled trial. Arch Intern Med. 2011;171:323-31.

49. Yu-Yahiro J, Resnick B, Orwig D, Hicks G, Magaziner J. Design and implementation of a home-based exercise program post-hip fracture: the Baltimore hip studies experience. PM R. 2009;1:308-18.

50. Thiebault RS, Funk MD, Abe T. Home-based resistance training for older adults: a systematic review. Geriatr Gerontol Int. 2014;14:750-7.

51. Hebert-Davies J, Laflamme G-Y, Rouleau D. HEALTH and FAITH investigators. Bias towards dementia: are hip fracture trials excluding too many patients? A systematic review. Injury. 2012:43:1978-84.

52. Huusko TM, Karppi P, Avikainen V, Kautiainen H, Sulkava R. Randomised, clinically controlled trial of intensive geriatric rehabilitation in patients with hip fracture: subgroup analysis of patients with dementia. BMJ. 2000;321: 1107-11.

53. Pitkälä KH, Pöysti MM, Laakkonen M-L, Tilvis RS, Savikko N, Kautiainen $H_{\text {, }}$ et al.. Effects of the Finnish Alzheimer disease exercise trial (FINALEX). A randomized controlled trial. JAMA Intern Med. 2013. https://doi.org/10.1001/ jamainternmed.2013.359.

54. Lawton MP, Brody EM. Assessment of older people: self-maintaining and instrumental activities of daily living. Gerontologist. 1969;9:179-86.

55. Granger CV, Hamilton BB, Zielezny M, Sherwin FS. Advances in functional assessment in medical rehabilitation. Top Geriatr Rehabil. 1986;1:59-74.

56. Guralnik J, Simonsick E, Ferrucci L, Glynn R, Berkman L, Blazer D, et al. A short physical performance battery assessing lower extremity function: association with self-reported disability and prediction of mortality and nursing home admission. J Gerontol. 1994:49:85-94.

57. Roberts HC, Denison HJ, Martin HJ, Patel HP, Syddall H, Cooper C, et al. A review of the measurement of grip strength in clinical and epidemiological studies: towards a standardized approach. Age Aging. 2011;40:423-9.

58. Sintonen $\mathrm{H}$. The $15 \mathrm{D}$ instrument of health-related quality-of-life: properties and applications. Ann Med. 2001;33:328-36.

59. Sintonen $\mathrm{H}$. The 15D-measure of health-related quality of life. I. Reliability, validity and sensitivity of its health state descriptive system. Melbourne: National Centre for Health Program Evaluation, Working Paper 41; 1994. https://pdfs.semanticscholar.org/64d2/

f291b61e8f7ca83cf890736cf52d2ead0a71.pdf. Accessed 3 July 2017

60. Sheikh JI, Yesavage JA. Geriatric depression scale (GDS): recent evidence and development of a shorter version. In: Brink TL, editor. Clinical gerontology: a guide to assessment and intervention. New York: The Haworth Press; 1986. p. 165-3.

61. Yardley L, Beyer N, Hauer K, Kempen G, Piot-Ziegler C, Todd C. Development and initial validation of the falls efficacy scale-international (FES-I). Age Ageing. 2005;34:614-9.

62. Kempen Gl, Yardley L, van Haasregt JC, Zijlstra GA, Beyer N, Hauer K, et al. The short FES-I: a shortened version of the falls efficacy scale-international to assess fear of falling. Age Ageing. 2008;37:45-50.

63. Cutrona CE, Russel DW. The provisions of social relationship and adaptation to stress. Adv Pers Relat. 1987:1:37-67.

64. Scott J, Huskisson E. Graphic representation of pain. Pain. 1976;2:175-84.

65. Bush K, Kivlahan DR, McDonell MB, Fihn SD, Bradley KA. The AUDIT alcohol consumption questions (AUDIT-C): an effective brief screening test for problem drinking. Ambulatory care quality improvement project (ACQUIP). Arch Intern Med. 1998;158:1789-95.

\section{Ready to submit your research? Choose BMC and benefit from:}

- fast, convenient online submission

- thorough peer review by experienced researchers in your field

- rapid publication on acceptance

- support for research data, including large and complex data types

- gold Open Access which fosters wider collaboration and increased citations

- maximum visibility for your research: over $100 \mathrm{M}$ website views per year

At BMC, research is always in progress.

Learn more biomedcentral.com/submissions 